\title{
POLÍTICA EXTERNA E INVESTIMENTOS BRASILEIROS EM ANGOLA ${ }^{1}$
}

\author{
Pietro Carlos de Souza Rodrigues ${ }^{2}$ \\ Sonia Delindro Gonçalves ${ }^{3}$
}

\section{Introdução}

A passagem da presidência de Fernando Henrique Cardoso para Luiz Inácio Lula da Silva foi, sem dúvida, um ponto de inflexão na orientação da política externa brasileira (Vigevani e Cepaluni 2007). Durante o mandato de Lula (2003-2010), o Brasil experimentou um constante aumento do fluxo de investimentos diretos. Neste contexto, multinacionais brasileiras começaram operações e exportações de serviços em países em desenvolvimento. Na África, Angola surge como o principal destino de investimentos brasileiros. Nesse sentido, as conexões entre política externa e internacionalização das empresas são fundamentais para entender o padrão recente das atividades econômicas das empresas brasileiras no país. Este artigo argumenta que as estratégias de internacionalização de empresas brasileiras em Angola estão relacionadas com os movimentos da política externa brasileira. Sugerimos, assim, que mudanças na política externa e incentivos governamentais têm peso significativo no perfil recente de investimentos estrangeiros diretos brasileiros.

Países africanos frequentemente são considerados enquanto portadores de instituições políticas menos seguras para os investimentos estrangeiros diretos (IED) (MIGA/World Bank Group 20I3)4. Entretanto, muitos países

I Uma primeira versão deste artigo foi apresentada no seminário da Associação Brasileira de Relações Internacionais (ABRI) 2015.

2 Doutorando no King's College London e na Universidade de São Paulo. Pesquisador do Centro de Estudos das Negociações Internacionais (CAENI/USP). E-mail:

pietro.rodrigues@kcl.ac.uk

3 Professora do Departamento de Administração e do Instituto Brasil do King's College London. Mestre e doutora em Economia pela London School of Economics. E-mail:

sonia.goncalves@kcl.ac.uk

4 Um dos principais rankings de risco político pode ser encontrado aqui: “Political Risk Index" 
da região passaram por processos de democratização a partir da década de I970, o que resultou em ambientes mais atrativos para a ação empresarial estrangeira (Pandya 20I4). Este processo, via de regra, incorporou setores sociais nas instituições políticas, ampliando também o papel das empresas na economia. Apesar do crescimento dos investimentos a partir dos anos I990 em países como a África do Sul, diversos países não se beneficiaram dos esforços de atração de investimentos, muito em razão das instabilidades políticas históricas da região, para além das dificuldades enfrentadas pelas economias (Collier e Gunning I999; Asiedu 2002). Portanto, manter boas relações com fontes de capital internacionais passou a ser um aspecto importante de muitos países africanos para promover investimentos em áreas sensíveis para o desenvolvimento das economias.

O Brasil passou, desde a década de I990, a ver seus investimentos diretos no exterior tornarem-se significativos em comparação com os países desenvolvidos (Motta Veiga e Rios 20I4; Fleury, Fleury, e Borini 20I3). Os países da América Latina foram, muitas vezes, os seus primeiros destinos, em virtude das proximidades culturais e das características socioeconômicas similares (Fleury, Fleury, e Borini 2013). Nos últimos anos, principalmente a partir do governo Lula (2003 - 2010), empresas brasileiras começaram a incursionar pela África e já se encontram presentes em boa parte dos países da região (Arbix e Caseiro 20II; Vilas-Bôas 20II). Como podemos ver na figura I, os investimentos brasileiros cresceram sensivelmente desde 2003.

O que faz com que os investimentos brasileiros se direcionem ao Sul? Algumas das sugestões encontradas na literatura aventam a hipótese de que a reorientação na política externa brasileira motivada pelo fim do mundo bipolarizado a partir dos anos I990, teve como característica distintiva o fortalecimento da cooperação sul-sul (Saraiva 2007; Milani e Carvalho 2013; Souza 20I2). Isso poderia também significar a intensificação dos fluxos econômicos. Se a mudança na orientação da política externa brasileira se expressa na busca pela redução de sua dependência com relação a poucos países (principalmente os do Norte) e pela maior autonomia de suas escolhas em matérias internacionais (Vigevani e Cepaluni 2007), ela pode ter efeitos sobre investidores brasileiros.

Como detalham Milani e Carvalho (2013, 13), os primeiros sinais de contraponto ao domínio dos países do Norte tem como marco a Conferência de Bandung, Indonésia, em I955. De lá para cá, até a criação da Agência Brasileira de Cooperação, muitas iniciativas foram formadas nesse sentido. Essa tendência, foi reanimada nos anos 2000, no mandato do governo Lula,

https://www.prsgroup.com/category/risk-index 
que buscou ampliar os laços com países do Sul, tanto bilateralmente como em instituições internacionais (Vigevani e Cepaluni 2007, 290). A promoção de investimentos e comércio é um dos principais instrumentos para o fortalecimento de relações bilaterais e, nesse sentido, é plausível aventar que o redirecionamento em termos políticos pode estar relacionado com o padrão de destinos dos investimentos brasileiros assumido recentemente.

Figura 1 - Evolução dos Investimentos Brasileiros Diretos (2001 - 2014)

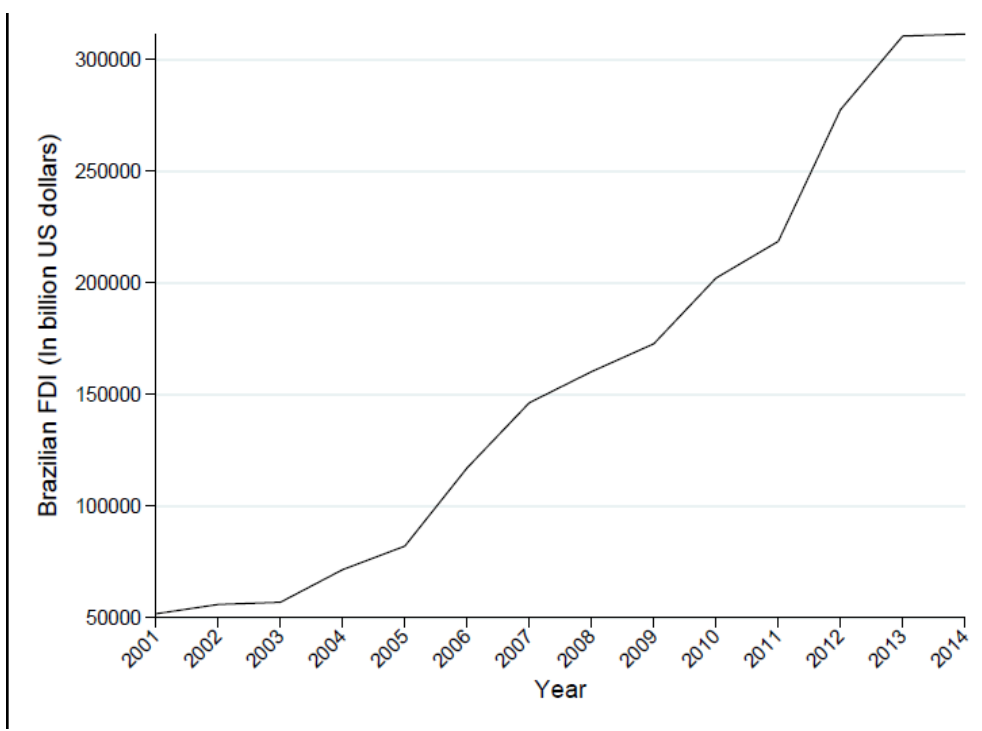

Fonte: os autores. A partir de dados do Banco Central do Brasil.

Dentre as ações empreendidas pelo governo brasileiro no contexto da Cooperação Sul-Sul, uma das que mais se destaca é a da Cooperação Internacional para o Desenvolvimento (CID) 5 . No discurso oficial, ela se caracterizaria pela horizontalidade da relação entre o país doador e país parceiro, pela preservação da autonomia do país receptor, pela ausência de condicionalidades e entendida como o importante mecanismo de promoção de desenvolvimento e estreitamento de relações entre países ${ }^{6}$. De acordo com Milhorance (2013),

5 Para a Agência Brasileira de Cooperação (ABC), a Cooperação Técnica Internacional (termo utilizado pela Agência) compreende "a ajuda financeira, o apoio técnico, a formação de recursos humanos, os processos de transferência de tecnologia, a doação de equipamentos e materiais, entre outros mecanismos, foram - e continuam sendo - amplamente utilizados na operacionalização da cooperação" (ABC). Mas, a definição da CID é alvo de controvérsias (Souza 20I2).

6 Do site oficial da Agência Brasileira de Cooperação (ABC) http://www.abc.gov.br/ 
a CID brasileira tem contribuído para o aumento do reconhecimento da confiança de países no hemisfério Sul com relação ao Brasil, especialmente em países da África de Língua Oficial Portuguesa (PALOPS).

Embora justificável a partir da mudança de paradigma da concepção de política exterior nacional, a cooperação brasileira na África tem sido questionada quanto ao insulamento das iniciativas em relação aos interesses privados nacionais (Duarte 20I4). Na visão de Souza (2OI2), a CID concedida por países em desenvolvimento, como o Brasil, é similar ao de países da OCDE7. Na visão do autor, "ambas são utilizadas como instrumento político-diplomático e de promoção de interesses econômicos, e não visam exclusivamente ou prioritariamente ao desenvolvimento dos países parceiros ou 'receptores'”(20I2, 9I). Olhar semelhante é o proposto por Apolinário Júnior (20I4), que demonstra como a cooperação brasileira poderia estar atrelada ao apoio ganho pelo Brasil dentro de instituições financeiras internacionais, como o FMI e o Banco Mundial.

Importantes recipiendários da cooperação para o desenvolvimento brasileiro na África, os PALOPS são também alguns dos destinos mais frequentes dos investimentos de empresas brasileiras na África. A política externa que privilegia o Sul, neste aspecto, é um drive importante da expansão das multinacionais brasileiras em direção ao continente. Ao comparar as práticas de cooperação internacional de Brasil, Índia e China, André de Mello e Souza (2OI2), destaca que as motivações da cooperação sul-sul são similares às oferecidas por países da OCDE, isto é, pode ser compreendida como um instrumento político-diplomático e, ao mesmo tempo, de promoção de interesses econômicos (p.91).

Ao passo em que está em curso a diversificação de destinos das empresas brasileiras, são necessárias novas explicações sobre os determinantes locacionais e perfil estratégico da internacionalização. Trabalhamos com a hipótese de que a relação entre variáveis políticas e os investimentos externos é crucial para o entendimento do papel da política sobre as decisões empresariais e sobre as escolhas em termos de incentivos para a internacionalização das empresas brasileiras. Dentre as possíveis novas interpretações destacam-se o tipo de relação que o Brasil estabelece com outros países, o apoio do governo brasileiro, acordos de cooperação e aspectos político-institucionais dos países de destino. Deste modo, os acordos internacionais estabelecidos pelo Brasil, o ambiente institucional dos países receptores e a proximidade política (e ideológica) entre estes e o governo brasileiro podem incentivar ações empresariais.

7 Esta visão é compartilhada por Milani (20I2). 
A dimensão política influencia os investimentos estrangeiros na medida em que a proximidade entre Estados pode afetar o comportamento dos investidores ao facilitar as interações entre agentes econômicos e, assim, diminuir as assimetrias de informações, reduzir os riscos de expropriação e favorecer investimentos (Gupta e Yu 2007) ${ }^{8}$. No caso dos investimentos norte-americanos no exterior, há evidências de que a proximidade política dos países receptores com os EUA reduz as assimetrias e custos de informação das empresas e, consequentemente, as barreiras de entrada $(2007,5)^{9}$. De modo similar, a proximidade política também pode reduzir riscos de expropriação. Ao avaliar os investimentos chineses, Duanmu (20I4) argumenta que a magnitude do risco ao qual estão submetidas essas empresas está associada a força das relações políticas entre o governo chinês e os países receptores. Esses mecanismos explicativos também podem ser indicativos dos investimentos brasileiros em Angola.

A política externa é um importante indutor dos investimentos brasileiros na África. Com o crescente volume de IED nos últimos anos e com a ampliação de ajuda estatal dedicada a eles, o problema ganhou relevância (Caseiro e Masiero 20I4). Este artigo busca lidar com esta questão endereçando informações que contribuem para essa compreensão de que interesses geopolíticos da estratégia de política externa brasileira podem estar vinculados a interesses econômicos. O caso de Angola é ilustrativo, neste sentido, da intrincada relação entre cooperação internacional para o desenvolvimento, políticas de internacionalização de empresas e interesses ideológicos de uma política externa autonomista. Neste artigo, vamos examinar algumas das principais abordagens para o papel da dimensão política para processos de internacionalização de negócios e analisar sugestões de literatura sobre as mudanças na política externa brasileira e seus possíveis efeitos económicos. A última etapa deste artigo será dedicada a expor alguns dos dados que sustentam nosso argumento.

\section{As relações entre Brasil e Angola}

Depois de um longo período de relações de baixa intensidade, a interação com os países da África lusófona tornou-se mais frequente. A criação da Comunidade dos Países de Língua Portuguesa em i996, durante o governo de Fernando Henrique Cardoso (I995 - 2002), é um exemplo importante

8 Os autores fazem uma ampla sistematização da literatura que vincula a influência das relações políticas sobre os fluxos econômicos, como os investimentos.

9 A redução das assimetrias de informação pode também facilitar processos de fusão e aquisição, na medida em que favorece articulações entre atores estrangeiros e domésticos. 
da evolução das relações (Vigevani, Oliveira, e Cintra 2003). No entanto, as circunstâncias e a intensidade das relações entre o Brasil e países africanos apenas mudaram a partir do governo de Luís Inácio Lula da Silva (2003 20IO). Como apontado por Visentini e Silva (20I0), a passagem do governo de Fernando Henrique Cardoso para Lula representa um novo capítulo em termos de importância dos países em desenvolvimento para a política externa brasileira.

Países africanos representam possíveis alianças estratégicas para as aspirações brasileiras em arenas multilaterais assim como oportunidades de mercado (Visentini e Silva 20Io). Estas características favoráveis começaram a ser melhor exploradas apenas durante o governo Lula. Inclusive, muitos consideram seu envolvimento pessoal no estreitamento dos laços com esses países (Visentini 20I4; Oliveira 20I5). Durante seu governo, Lula visitou oficialmente Angola três vezes $(2003,2007 \text { e } 2010)^{\mathrm{IO}}$, assinou 45 acordos bilaterais com o país ${ }^{\mathrm{II}}$ e se posicionou como um interlocutor ativo entre a América do Sul e Países Africanos (por seu papel no Fórum IBAS e Cúpula América do Sul-África, por exemplo)

De acordo com Barbosa et al. (2009), economia e política são necessários para compreender a política externa brasileira na África. Conforme relatado pelos autores, as oportunidades para as exportações e internacionalização de empresas brasileiras influenciaram a disposição do Brasil para a cooperação no continente. No entanto, apontam os autores, esse fato não é condição suficiente para dizer que o país exerce um papel de potência emergente na área. Há ainda uma certa dependência regional em relação a China e os EUA em particular, que coloca o Brasil em uma posição frágil para exercer interesses geoestratégicos na região.

Uma compreensão ligeiramente diferente sobre a presença brasileira na África é discutida por White (2010). Para o autor, a abordagem brasileira para o continente é relativamente bem sucedida porque se baseia em três importantes fatores. Combinando os [I] interesses económicos através da internacionalização de suas empresas com [2] visitas presidenciais, parcerias estratégicas (por exemplo, IBSA) e [3] projetos de cooperação, o Brasil conseguiu aumentar sua influência como potência emergente na África. No entanto, aponta o autor, sua posição ainda é relativamente frágil em comparação com a Índia e a China. O que diferencia a política externa brasileira da indiana e chinesa é a pluralidade de atores - agências, empresas e ações governamen-

Io Ter escolhido visitar o país em seu primeiro ano de governo é indicativo da importância estratégica que Angola tem agora para o governo.

II Os dados podem ser encontrados na base de dados do Ministério das Relações Exteriores do Brasil (http://dai-mre.serpro.gov.br/) 
tais - envolvidos nas relações bilaterais. Mais do que a presença de fato, estas características melhoram o soft power brasileiro no continente e asseguram a boa imagem do País. As consequências dessas características podem ser aferidas pelo apoio frequente de países africanos às posições brasileiras em fóruns multilaterais (White 20I0).

Entre os países africanos, Angola tem um papel de destaque na política externa brasileira. Em I975, após os movimentos de emancipação, o Brasil foi o primeiro país a reconhecer a independência de Angola. No ponto de vista de Lima (2005), o reconhecimento do primeiro governo independente de Angola durante o governo militar é um marco da diplomacia autônoma e ativa brasileira no continente africano (Lima 2005, 28). Estas relações, no entanto, só vão se fortalecer a partir dos anos 90, com a visita de Fernando Henrique Cardoso à região e o consecutivo adensamento das relações comerciais do Brasil e das negociações do MERCOSUL com a SADC ${ }^{\mathrm{I} 2}$. Durante o governo de FHC, o envio de missões tropas é considerado por Vigevani et al. como um passo para a retomada do interesse de empresas brasileiras pelo país (Vigevani, Oliveira, e Cintra 2003, 55).

Porta de entrada do Brasil no continente africano, Angola tem experienciado taxas de crescimento econômico elevadas na última década ${ }^{13}$. Com uma média de crescimento de I0\% a.a. entre $200 \mathrm{I}$ e $2013^{\mathrm{I} 4}$, a renda per capita angolana alcançou US\$5.I70 mil, em 2013 (frente a US\$7.604 mil, que é a média dos países em desenvolvimento de renda média alta - Upper Middle Income Countries na definição do Banco Mundial). A quinta maior economia africana tem recebido atenção por parte de empresas brasileiras em virtude de oportunidades de negócios em áreas críticas para o país, como o petróleo, que representa $46 \%$ de seu PIB e $96 \%$ de suas exportações (Banco Mundial 20I3), mineração, agricultura e infraestrutura (Iglesias e Costa 20II). Com essas características, Angola recebe investimentos brasileiros de empresas do setor petrolífero e de construção desde o final dos anos I970 (Iglesias e Costa 2OII $)^{15}$, e tornou-se, em tempos recentes, um dos principais receptores de

I2 Comunidade para o Desenvolvimento da África Austral. Integrado por África do Sul, Angola, Botswana, República Democrática do Congo, Lesoto, Madagascar, Malawi, Mauricia, Moçambique, Namíbia, Suazilândia, Tanzânia, Zâmbia e Zimbabwe.

I3 A economia angolana apresentou crescimento da ordem de I8\% em 2006, 23\% em 2007 e I $4 \%$ em 2008. Após a crise de 2008 , que afetou os preços do petróleo e a ida de IED para o País, a economia se desaqueceu. Entretanto, voltou a ganhar fôlego em 20II (4\%) e em 2013 já apresentou um crescimento da ordem de $7 \%$.

I4 Dados retirados a partir de levantamentos do Banco Mundial (http://data.worldbank.org/ data-catalog/world-development-indicators)

I5 A Petrobrás se instala no país em i979. A Odebrecht começa suas atividades em Angola em I984. 
investimentos brasileiros no continente (US\$I.3 bi em 2013).

A atratividade estratégica da economia angolana para as empresas brasileiras também se refletiu em oportunidades para as exportações. De $200 \mathrm{I}$ a 2014 as exportações ${ }^{16}$ para o país africano cresceram mais de 8 vezes e isto fez com que o país se tornasse o segundo maior parceiro comercial brasileiro na África Subsaariana (Ministério das Relações Exteriores 20I3). Para Angola, o Brasil está entre os três países de maior importância e influência (Iglesias e Costa 20II, I6) ${ }^{17}$.

Figura 2 - Cartograma da distribuição dos Investimentos Brasileiros no Mundo $-2014$

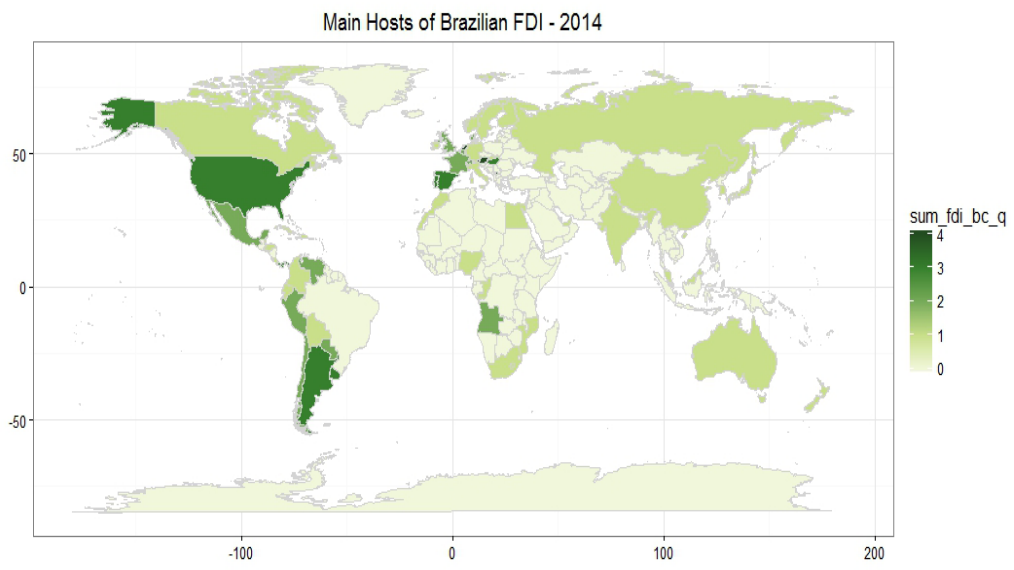

Fonte: os autores. Com base em dados do Banco Central do Brasil. Verde Claro (pouco ou nenhum investimento - verde escuro (auto volume de estoque de investimento)

O modelo de comércio brasileiro em Angola tem como um de seus fundamentos a concessão de créditos do Banco Nacional de Desenvolvimento Econômico e Social (BNDES) para o financiamento de exportações de bens e serviços para obras de infraestrutura, com garantias recebíveis de petróleo. De acordo com Vilas-Bôas (20I4), Angola não é o único país a receber este tipo de financiamento, mas é o único país a ter uma conta especial (a conta petróleo $)^{18}$. O financiamento de exportações de bens e serviços de infraestru-

I6 O que representou, em 20I4, a quantia de US\% ,2 bi (Ministério do Desenvolvimento, Indústria e Comércio Exterior 2015).

I7 A título de exemplo, a construtora brasileira Norberto Odebrecht é a maior empregadora privada do país (Vieitas e Aboim 2012).

I8 Uma reportagem especial sobre a questão pode ser vista no Valor Econômico (02/05/20I2). Acesso em 20 de maio de 2016 . http://www.valor.com.br/brasil/2640008/brasil-quer-replic- 
tura do BNDES para Angola tem beneficiado, pelo menos desde 2007, algumas das empresas campeãs nacionais do ramo de construção, como as construtoras brasileiras Odebrecht, Camargo Correa, Queiroz Galvão e Andrade Gutierrez. Ao passo em que se consolida a participação de empresas brasileiras na região, é interessante, como sugere Vilas-Bôas (20I4), que os principais contratantes dos financiamentos das empresas de engenharia são governos. Desse modo, as empresas de construção em Angola, por razão da existência da conta petróleo, têm sido beneficiadas diretamente pelas relações entre o governo do país e o governo brasileiro.

\section{Aspectos políticos dos Investimentos brasileiros em países em desenvolvimento}

O investimento estrangeiro, no geral, e a internacionalização de empresas, em particular, são objetos de estudo de diversas áreas das ciências humanas e constituem até mesmo a base de uma área do saber, os chamados negócios internacionais ${ }^{19}$. Embora a área de negócios internacionais não tenha exclusividade sobre os temas, o campo é referência comum para a maior parte dos pesquisadores. É a partir do debate travado nessa esfera que são formuladas as principais teorias explicativas sobre as trajetórias, estratégias, causas e efeitos da internacionalização.

O modo mais usual de compreensão da internacionalização das empresas brasileiras é entendê-la como uma etapa posterior às exportações. Em situações nas quais determinados mercados têm peso elevado nas exportações da empresa, nada mais natural do que abrir subsidiárias, escritórios de representação e/ou assistência técnica: são os primeiros passos para a internacionalização (CNI 20I3, 45). Também outras explicações são frequentemente apontadas como razões para a internacionalização de empresas brasileiras, tais como a diversificação das estratégias e a minimização de riscos quanto ao ciclo econômico do Brasil (Hiratuka e Sarti 20II), o acesso a novas tecnologias (Arbix, Salerno, e Negri 2005), a redução de custos e aprendizado para enfrentar a concorrência internacional (Cyrino e Tanure 2009), a melhora do ambiente macro e microeconômico doméstico (Casanova e Kassum 20I3) e os incentivos e financiamentos do país de destino (Caseiro 2013).

Tão logo começaram a proliferar exemplos de internacionalização de

ar-com-outros-paises-da-africa-modelo-de-comercio-com-angola

I9 A área mantém um debate amplo sobre os temas e conta com pesquisadores de campos como a administração, economia, ciência política, relações internacionais, sociologia, antropologia e psicologia. 
empresas oriundas de países em desenvolvimento, as principais abordagens explicativas dos determinantes de sua internacionalização passaram a ser questionadas quanto a sua adequação para a compreensão dos contextos de mercados emergentes (Cuervo-Cazurra 20I2; Cuervo-Cazurra e Ramamurti 20I4). Apesar de muito disseminadas, essas explicações são alvo de controvérsias principalmente quanto às motivações e destinos do IBD. Os autores que trabalham com o modelo de Uppsala, no qual os investimentos brasileiros no exterior são vistos como resultado de estratégias graduais, começaram a ser questionados muito em razão do perfil que os investimentos brasileiros assumiram a partir de 2004 (Arbix e Caseiro 20II; Casanova e Kassum 2013) ${ }^{20}$. No entendimento de Arbix e Caseiro (2012), recentemente tanto as estratégias das firmas quanto o suporte político institucional brasileiro alteraram as disposições de expansão das multinacionais brasileiras. Dentre as explicações dos autores, destaca-se o apoio estatal para a criação de grandes grupos de negócios com presença no mercado globalizado.

As novas abordagens destacam estratégias de inserção internacional inovadoras dessas empresas (Mathews 2006), as habilidades desenvolvidas para lidar com ambientes institucionais com incertezas (Guillén e García-Canal 2009), as vantagens comparativas derivadas do contexto do país de origem (Rugman e Verbeke 2004; Fleury, Fleury, e Borini 2013) e estratégias de adaptação e que valorizam vantagens específicas e reduzem os riscos de serem estrangeiras (Ramamurti e Singh 2009). O olhar sobre o contexto de origem das multinacionais de emergentes trouxe relevância para o papel das instituições nas decisões empresariais (Kostova e Zaheer I999; Kostova e Roth 2002). Esta e as demais perspectivas citadas têm sido incorporadas aos estudos de internacionalização, embora ainda muito detidos aos incentivos e relações entre empresas e as burocracias dos países de origem e receptores dos investimentos.

A literatura brasileira de Relações Internacionais tem dado cada vez mais atenção ao papel desempenhado pelas transnacionais brasileiras na inserção internacional do Brasil (Sennes e Mendes 2009; Jank e Tachinardi $2007)^{21}$. Em muitas ocasiões, as articulações público-empresariais empreendidas pelo governo brasileiro visam aumentar sua presença internacional por

20 Para esses pesquisadores, as empresas primeiro se instalam em países vizinhos (América Latina) e depois seguem para regiões mais afastadas (Fleury, Fleury e Borini 20I3; Parente et al. 20I3). Estas explicações se baseiam, via de regra, no argumento de que a proximidade cultural e geográfica reduz os riscos dos investimentos das empresas.

2I São vários os exemplos encontrados na literatura. Ver: (Iglecias 20II; Alves 20II; Menezes 20I2; Vianna 20I0; Caseiro e Masiero 20I4; Alem e Cavalcanti 2005; Vasconcellos 20I4; Campielo e Pesavento 2013; Carvalho 2012). 
meio da expansão das atividades produtivas de empresas brasileiras no exterior.

Os incentivos públicos à internacionalização estão, muitas vezes, atrelados a programas de cooperação para o desenvolvimento internacional em regiões nas quais o país busca aumentar sua influência ${ }^{22}$. A internacionalização de empresas como a Embrapa, a Fiocruz, a Sabesp, entre outras, é fortemente estimulada por meio de incentivos gerados a partir de programas da Agência Brasileira de Cooperação ${ }^{23}$ (Barbosa 20I2). Em geral, estes programas buscam replicar a expertise nacional em projetos nas áreas de saneamento, desenvolvimento agrícola e habitação - conhecimento do qual muitos países em desenvolvimento podem se beneficiar, aproveitando-se das experiências adquiridas por estas empresas no Brasil.

Nos temas de integração regional, a internacionalização das empresas brasileiras é frequentemente incentivada pelo governo com o intuito de fortalecer sua presença regional a partir de projetos de grande porte. Empresas privadas da área de infraestrutura, como importantes construtoras brasileiras - Odebrecht, Camargo Correa, Andrade e Gutierrez e Queiroz Galvão, para citar as mais conhecidas - são importantes agentes em projetos relacionados a obras regionais de energia, infraestrutura, logística e transporte (VilasBôas 20II; Luxemburg 2009; Couto 2008; Vasconcellos 20I4; Castro 20I2). Outras empresas nacionais fazem parte do grupo beneficiado pelo governo brasileiro nestas áreas, como são exemplos a Petrobrás e a Vale do Rio Doce.

Também em áreas estratégicas para o desenvolvimento nacional, de maior intensidade tecnológica, as ações do governo brasileiro têm cumprido papel relevante na internacionalização de empresas brasileiras (Arbix, Salerno, e Negri 2005). Aquelas com alto grau de especialização tecnológica e potencial de inovação como a Embraer, a Marcopolo, Weg e Braskem²4 são amparadas por instituições governamentais que visam a obtenção de conhecimento e tecnologia no exterior, ao mesmo tempo em que garantem a inserção competitiva do Brasil em setores de ponta. A presença internacional destas empresas assegura ao governo a participação brasileira em mercados globais

22 Ver (Guimarães 200I; Sennes e Mendes 2009)

23 Exemplo é o programa Pro-Savana, no qual o governo brasileiro (por meio da Agência Brasileira de Cooperação em parceria da Embrapa) busca desenvolver, em áreas de savana no continente africano, frentes de desenvolvimento agroindustrial similares ao sucesso da adaptação de culturas do cerrado brasileiro (que possui condições próximas às savanas africanas). As potencialidades deste programa, além das externalidades para algumas economias africanas, podem resultar em oportunidades de investimentos para os empresários do agronegócio brasileiro. Ver: http://www.cnpmf.embrapa.br/destaques/Mocambique.pdf.

24 Estudos de caso sobre a trajetória de internacionalização destas empresas podem ser vistos em (Parente et al. 20I3) 
estratégicos, como as áreas de segurança e defesa, transporte, energia, entre outros.

Conforme apontado, o Brasil tem fomentado instituições para a promoção do comércio e investimentos brasileiros no exterior, como a Agência Brasileira de Promoção de Exportações e Investimentos (APEX) e o Banco Nacional de Desenvolvimento Econômico e Social (BNDES), que cumprem papéis essenciais no apoio à internacionalização de empresas brasileiras ${ }^{25}$.

É do interesse do empresariado que o governo brasileiro celebre acordos em busca de oportunidades de investimentos e de compromissos credíveis sobre os investimentos realizados no exterior, com especial atenção ao seu papel em países em desenvolvimento e de economia centralizada. Do ponto de vista das empresas, tal interesse pode derivar, para além das garantias dos direitos sobre os investimentos, das vantagens criadas pela presença governamental brasileira. A obtenção de permissões e acesso ao conhecimento, tecnologias e ativos estratégicos pode ser facilitada às empresas brasileiras que já atuam no exterior, a depender do tipo de presença que o governo brasileiro estabelece com o país hospedeiro do investimento. Particularmente, acordos de desenvolvimento tecnológico e cooperação técnica podem favorecer as atividades das empresas brasileiras, aumentando sua competitividade ou significando oportunidades privilegiadas de negócios.

\section{Política Externa Brasileira e Investimentos em Angola}

Entendidas como riscos políticos para os investimentos, as possibilidades de ações discricionárias dos países estão ligadas às características do ambiente político-institucional dos países que recebem investimentos. Tais práticas e decisões podem se dar em função de compreensões difusas sobre os impactos dos investimentos estrangeiros (Jensen e Lindstädt 2013), e podem estar relacionadas à indicadores de qualidade institucional (Buchanan, Le, e Rishi 20I2). Os riscos políticos, de acordo com Henisz (2000), impactam tanto a decisão de ida ao estrangeiro quanto ao modo de entrada das empresas em um país, e "é função não apenas da estrutura do ambiente institucional mas também das características da transação do investimento” (p.335). Em

25 O "Relatório dos Investimentos Brasileiros no Exterior 20I3", organizado pela CNI prescreve algumas atribuições desejáveis de serem adotadas pelo governo brasileiro com vistas a fomentar a internacionalização de empresas. Entre as recomendações estão a) a coordenação de iniciativas de promoção de investimentos (diplomacia econômica); b) a defesa dos interesses das empresas brasileiras junto aos países de destino dos investimentos, principalmente em países em desenvolvimento e c) a negociação de acordos de promoção e proteção dos investimentos (APPIs), de modo a mitigar riscos políticos (CNI 20I3, I2). 
ambientes institucionais de alto grau de incerteza, como o caso de Angola, conexões políticas e acordos internacionais entre governos podem ter função importante na redução de riscos políticos (Büthe e Milner 20I2; Guerin e Manzocchi 2009; Jensen 2008) ${ }^{26}$. Instituições domésticas são importantes para a atração de IED (Jensen 2003) e inconsistências na atração de investimentos podem ocorrer devido à falta de garantias dos investidores de que os governos não empreenderão medidas que os afetem negativamente (Büthe e Milner 20I2, 35), como são exemplos a nacionalização forçada de empresas, a taxação de remessas de lucro, a corrupção, entre outros (Busse e Hefeker 2007; Xu e Shenkar 2002) ${ }^{27}$. Além de afetar as decisões de IED a partir da alteração de custos variáveis, a afinidade de orientação ideológica dos governos receptores e de origem das empresas pode, de acordo com Schneider e Frey (I985), incentivar o fluxo de investimentos entre os países na medida em que facilita a abertura de canais de comunicação, promove a cooperação entre as partes e reduz assimetrias de informação ${ }^{28}$.

São muitas as sugestões encontradas na literatura sobre a maneira como as escolhas políticas dos países afetam a disposição de investimento e comércio das empresas nacionais. Ao observarmos o comportamento de algumas empresas brasileiras na África, esta relação parece ser ainda mais evidente. Com base em uma série de dados descritivos sobre os investimentos, comércio, projetos de cooperação e auxílios do BNDES à operações de empresas em Angola, corrobora-se com os argumentos aventados na literatura dos ganhos econômicos incentivados pelos incentivos do governo e pelas ações da política externa brasileira, ora chamada de Cooperação Sul-Sul ${ }^{29}$.

Segundo levantamento da Fundação Dom Cabral (20I4), I2 das Ioo empresas brasileiras mais transnacionalizadas operam em Angola. Dentre as empresas brasileiras que operam no país, figuram ao menos 7 construtoras, passíveis de receber benefícios de financiamento governamentais indiretos. O BNDES, que conta com uma linha especial de crédito para a compra de

26 De acordo com Büthe e Milner (20I2), quanto mais democrático é um país, maior é o efeito de acordos preferenciais e de livre comércio sobre nível de investimentos no país. Explicação similar é a de Tuman e Emmert (2004), para os quais as firmas que buscam expandir seus mercados podem ser atraídas a um país quando este participa de acordos regionais de livre comércio ou uniões aduaneiras.

27 Alguns tipos de riscos político-institucionais foram melhor detalhados por Henisz (2000). 28 No caso brasileiro, como interpretam Vigevani e Cepaluni (2007), a "experiência do governo Lula da Silva sugere significativo peso das ideias, temperadas pelos constrangimentos das realidades internacionais - políticas, econômicas e estratégicas." (p. 276).

29 Assume-se aqui o pressuposto de que os financiamentos do BNDES são indicativos de proximidade política do governo brasileiro com o país de destino das exportações de bens e serviços. 
serviços de empresas brasileiras por clientes estrangeiros, beneficiou algumas das empresas mais importantes do setor de construção. Os dados de financiamento do banco às exportações de empresas de bens e serviços de engenharia demonstram que, no período de 2007 a 20I4, Angola foi o país que mais recebeu pela modalidade. Dentre as empresas beneficiadas, destacam-se Queiroz Galvão, Andrade Gutierrez, Camargo Correa e, principalmente, a Odebrecht, presente no país desde a década de i980.

\section{Figura 3 - Desembolso do BNDES por firma, ano e país}

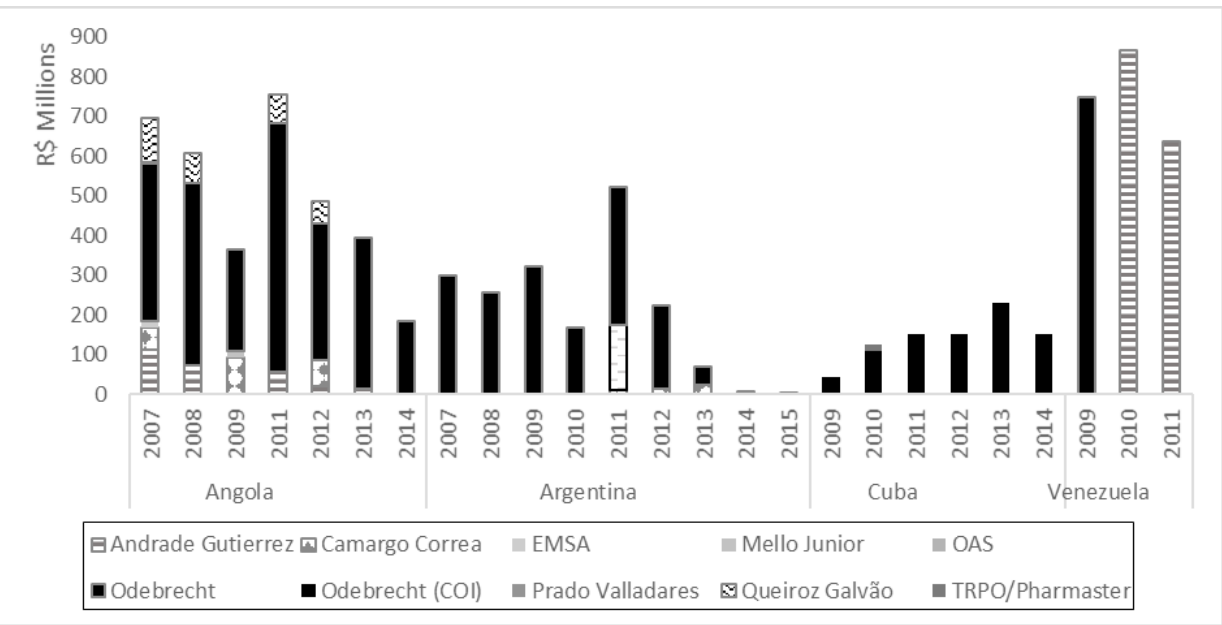

Fonte: os autores. Baseados em dados do BNDES (2015).

A lista dos principais países que compõem os destinos preferenciais dos benefícios do BNDES não é sintomática do papel das afinidades políticas e ideológicas entre o governo brasileiro e os países parceiros. Uma das maneiras de se verificar esta conexão é averiguando o alinhamento em temas internacionais destas economias com relação ao Brasil. Dentre os trabalhos que buscam encontrar similaridades e proximidades entre os países a partir das posições tomadas em organismos internacionais, destaca-se os que olham para o padrão de votação dos representantes na Assembleia Geral das Nações Unidas (Voeten 2000; Gartzke 2000).

Por ser de amplo escopo, o alinhamento a partir das votações na AGNU é frequentemente considerado um bom indicador de afinidade entre os países ${ }^{30}$. Exemplos na literatura de política externa brasileira são relevantes.

30 Esses dados, foram sistematizados e disponibilizados ao público por Erik Voeten, e estão disponíveis em Harvard Dataverse Network (https://thedata.harvard.edu/dvn/). 
Amorim Neto (Amorim Neto 20II) avalia o peso relativo de variáveis políticas domésticas e sistêmicas na determinação da política externa brasileira. Particularmente, é do interesse do autor demonstrar como a convergência das votações entre o Brasil e os Estados Unidos na Assembleia Geral das Nações Unidas é um bom indicativo das alterações da orientação da Política Externa brasileira ao longo do tempo. De maneira semelhante, Malamud (20II) avalia em que medida o Brasil pode ser compreendido como um líder regional a partir da semelhança de votos do país com outros países da região. Ramanzini e Ribeiro (2013) comparam convergência entre Brasil e China com alguns dos principais parceiros estratégicos de ambos os países. Os achados dos autores fortalecem as hipóteses de que o alinhamento político entre o Brasil e a China é seguido pelo aumento das relações de comércio e investimentos entre os países.

Figura 4: Convergência de votos na Assembleia Geral das Nações Unidas (2001 - 2012)

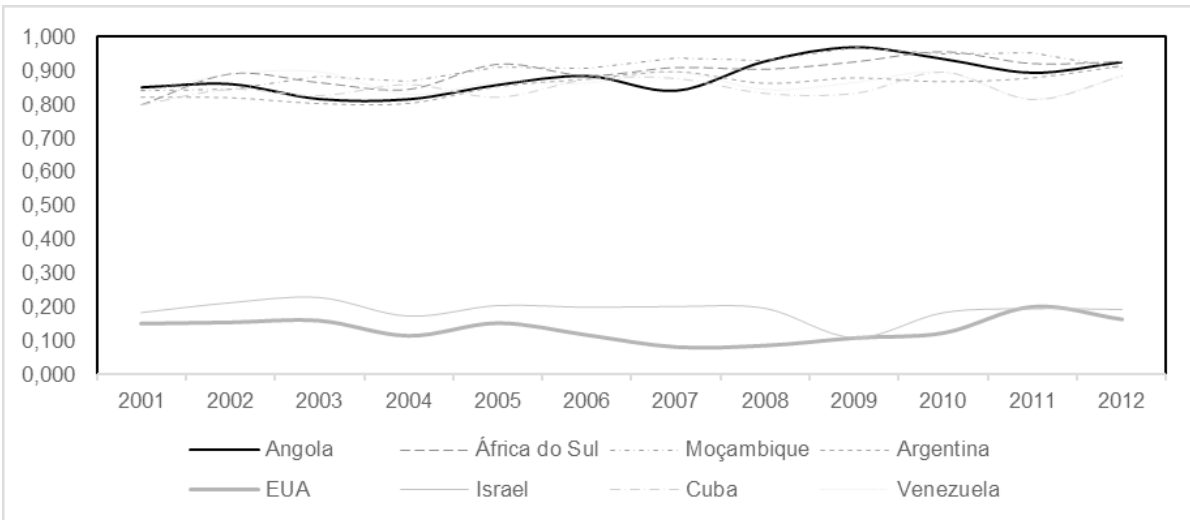

Fonte: os autores. Dados de Bailey, Strezhnev e Voeten (2015).

Como é possível observar na figura acima, Angola teve um comportamento altamente alinhado com o Brasil no que se refere ao padrão de votações do país na AGNU no período de $200 \mathrm{I}$ a 20I2, alinhamento este parecido com o de outros países que também são destinos comuns dos incentivos às exportações do BNDES, nomeadamente, Argentina, Cuba e Venezuela. Ao nos determos mais detalhadamente à variação da convergência na AGNU entre Angola e Brasil, percebemos que no período entre 2006 e 2011 o alinhamento esteve em seu período de auge. Coincidentemente, como podemos observar na figura abaixo, este também foi o período de crescimento [I] do número de projetos de cooperação entre Brasil e Angola, [2] de maior volume de desem- 
bolso do BNDES para empresas brasileiras, [3] maior volume de exportações brasileiras para o país. Também, o período compreende três viagens oficiais realizadas por Lula ao país $(2003,2007$ e 2010).

Figura 5 - Número de Projetos de Cooperação, Desembolso do BNDES, IBD e Exportações para Angola (2001 - 2014)

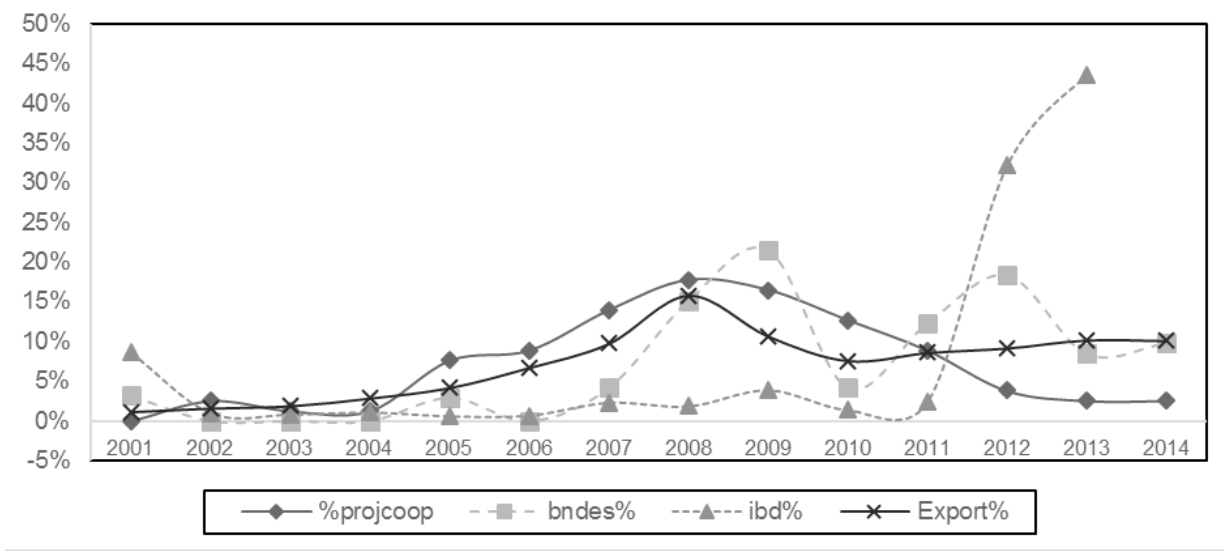

Fonte: os autores. Com base em dados do Aid Data 3.0, BNDES, Banco Central do Brasil e MDIC.

Testes estatísticos preliminares sugerem uma relação positiva entre as variáveis - relação que é ainda maior quando se consideram de modo defasado as variáveis de investimento e comércio. Os resultados não foram trazidos à análise pela ausência de dados mais robustos capazes de permitir sugestões mais elaboradas de causalidade. No entanto, um teste simples correlação aponta os valores de 0,67 entre cooperação (projcoop) e votos na Assembléia Geral das Nações Unidas (AGNU), o,87 entre as exportações e cooperação e de 0,80 entre os votos na Assembleia Geral da ONU e ao financiamento das exportações fornecidos pelo BNDES. Embora evitamos trazer teorias mais elaboradas sobre os efeitos da cooperação brasileira sobre o fluxo de investimentos brasileiros em Angola, é plausível argumentar que a atividade econômica brasileira em Angola, parcialmente captada pelos investimentos e pelas exportações, está relacionada com eventos políticos envolvendo os dois países. No caso das exportações, existe uma clara relação entre o aumento das atividades de política externa do Brasil (visitas oficiais, votos na AGNU e projetos de cooperação) e o aumento das exportações.

Embora esta relação não seja clara no caso dos investimentos, é razoável interpretar que as empresas brasileiras em Angola se beneficiam das 
ações da política externa brasileira, especialmente grandes grupos de engenharia. Se considerarmos as exportações de serviços como um sinal de atividade direta de empresas em Angola, parece-nos claro que o estímulo fornecido pelo BNDES funciona como um mecanismo fundamental de ligação entre o governo brasileiro e o cliente receptor, que principalmente é, neste caso, o governo angolano. As empresas, beneficiárias finais desta relação, reforçam por sua vez a presença brasileira no País. A causalidade não é clara, mas estas evidências parecem nos mostrar que há uma complementaridade entre os interesses governamentais e privados por detrás das relações bilaterais entre Brasil e Angola nos últimos anos.

\section{Considerações Finais}

Ao tratar dos investimentos brasileiros na África, Souza (2012) sugere que a cooperação brasileira para o desenvolvimento tem contribuído para o financiamento da importação de bens e serviços do país, sobretudo pelo BNDES. Os dados aqui dispostos vão de encontro com os apontamentos do autor e destacam que entre $200 \mathrm{I}$ e 2014, empresas brasileiras se beneficiaram do alinhamento político brasileiro com relação a Angola. O comportamento de Angola e Brasil na Assembleia Geral das Nações Unidas e o número de projetos de cooperação firmados entre os países, permitem o argumento dos benefícios econômicos das empresas brasileiras associados ao alinhamento político internacional.

A busca da autonomia como objetivo precípuo da orientação da política externa brasileira - na qual as políticas se orientam em torno da Cooperação Sul-Sul em contraposição ao parâmetro hegemônico da Cooperação Norte-Sul - pode induzir o comportamento externo das empresas brasileiras. O entrelaçamento entre a política externa e estratégias de internacionalização de empresas brasileiras pode ser visto como um importante fator para a operação das empresas brasileiras em países em desenvolvimento, e em Angola em particular.

\section{REFERÊNCIAS}

Alem, Ana Claudia, e Carlos Eduardo Cavalcanti. 2005. “O BNDES E O Apoio À Internacionalização Das Empresas Brasileiras: Algumas Reflexões.” Revista Do BNDES I2 (24): 43-76.

Alves, Rodrigo Maschion. 20II. "O Investimento Externo Direto Brasileiro : A América Do Sul Enquanto Destino Estratégico.” Meridiano 47 I2 
(I27): $25-35$.

Amorim Neto, Octavio. 20II. De Dutra a Lula: A Condução E Os Determinantes Da Política Externa Brasileira. Rio de Janeiro: Elsevier.

Apolinário Júnior, Laerte. 20I4. “Formação de Coalizões Dentro Das Instituições Financeiras Internacionais: O Caso Do Brasil No FMI E Banco Mundial.” Dissertação de mestrado, Universidade de São Paulo.

Arbix, Glauco, e Luiz Caseiro. 20Iı. "Destination and Strategy of Brazilian Multinationals." Economics, Management and Financial Markets 6 (I): I-35.

Arbix, Glauco, e Luiz Caseiro. 20I2. "Determinants of the Recent Internationalization of Brazilian Companies." In Third Copenhagen Conference on Emerging Multinationals: Outward Investment from Emerging Economies, 25-26. Copenhagen.

Arbix, Glauco, Mario Sergio Salerno, e João Alberto De Negri. 2005. “O Impacto Da Internacionalização Com Foco Na Inovação Tecnológica Sobre as Exportações Das Firmas Brasileiras.” Dados 48 (I): 395-442.

Asiedu, Elizabeth. 2002. "On the Determinants of Foreign Direct Investment to Developing Countries : Is Africa Different?” 30 (I): I07-I9. http:// www.sciencedirect.com/science/article/pii/So305750Xогоoıooo.

Bailey, M, Anton Strezhnev, e Erik Voeten. 2015. "Estimating Dynamic Dtate Preferences from United Nations Voting Data." Available at SSRN 2330913. doi:Io.II77/0022002715595700.

Banco Mundial. 2013. “Angola Economic Update.” Angola Economic Update. Luanda.

Barbosa, Alexandre de Freitas, Thais Narciso, e Marina Biancalana. 2009. "Brazil in Africa: Another Emerging Power in the Continent?" Politikon 36 (9243I7474): 59-86. doi:Io.Io80/02589340903I5540I.

Barbosa, Pedro Henrique Batista. 20I2. “O Viés Instrumental Da Cooperação Técnica.” Tempo Do Mundo 4 (I): I2I-53.

Buchanan, Bonnie G., Quan V. Le, e Meenakshi Rishi. 20I2. "Foreign Direct Investment and Institutional Quality: Some Empirical Evidence.” International Review of Financial Analysis 2I (24). Elsevier Inc.: 8I-89. doi:Io.Ior6/j.irfa.20II.Io.ooI.

Busse, Matthias, e Carsten Hefeker. 2007. "Political Risk, Institutions and Foreign Direct Investment." European Journal of Political Economy 23 (2): 397-4I5. doi:Io.Ioi6/j.ejpoleco.2006.02.003.

Büthe, Tim, e Helen V Milner. 20I2. "The Interaction of International and Domestic Institutions: Preferential Trade Agreements, Democracy, 
and Foreign Direct Investment." New Orleans.

Campielo, Renata de Siqueira, e Fábio Pesavento. 2013. "A Política Externa Brasileira E O BNDES : Uma Análise Da Atuação Internacional Do BNDES Durante O Governo Lula (2003-2010)." In $2^{\circ}$ Seminário de Iniciação Científica ESPM, I-I6.

Carvalho, Carlos Eduardo, e Ricardo Sennes. 2009. "Integração Financeira E Internacionalização de Empresas Brasileiras Na América Do Sul.” Nueva Sociedad.

Carvalho, Clarissa Barbosa Ramos Prudêncio. 2012. "O Protagonismo Do BNDES No Financiamento Da Infraestrutura Sul-Americana Durante O Governo Lula: Interface Entre Interesses Domésticos E a Política Externa." In Associação Brasileira de Relações Internacionais - ABRI, I-2I. Brasília.

Casanova, Lourdes, e Julian Kassum. 2013. "Brazilian Emerging Multinationals : In Search of a Second Wind.” Working Papers. http://research. insead.edu/2013/05/CasanovaKassum_2r.html.

Caseiro, Luiz, e Glauco Arbix. 2012. "Characteristics and Determinants of The Recent Internationalization of Brazilian Companies," no. October: $25-26$.

Caseiro, Luiz Carlos Zalaf. 20I3. "Novas estratégias de internacionalização de empresas brasileiras: expansão geográfica, determinantes e alternativas de política industrial." Dissertação de mestrado, Universidade de São Paulo. http://www.teses.usp.br/teses/disponiveis/8/8132/tde290I20I4-I04503/.

Caseiro, Luiz Carlos Zalaf, e Gilmar Masiero. 20I4. "OFDI Promotion Policies in Emerging Economies: The Brazilian and Chinese Strategies." Critical Perspectives on International Business Io (4): 237-55. doi:Io.IIo8/ cpoib-03-2014-0023.

Castro, Edna. 20I2. "Expansão Da Fronteira, Megaprojetos de Infraestrutura E Integração Sul-Americana.” Caderno CRH 25 (64): 45-62. doi:org/10.1590/SoI03-49792012000100004.

CNI, Confederação Nacional da Indústria. 2013. "Relatório Dos Investimentos Brasileiros No Exterior 20I3 - Recomendações de Políticas Públicas Para O Brasil." Brasilia.

Collier, Paul, e Jan Willem Gunning. I999. "Why Has Africa Grown Slowly ?" The Journal of Economic Perspectives I3 (3): 3-22.

Couto, Leandro Freitas. 2008. “A Iniciativa Para a Integração Da Infra-Estrutura Regional Sul-americana-IIRSA Como Instrumento Da Política 
Exterior Do Brasil Para a América Do Sul.” OIKOS 5 (I): I8. http:// www.revistaoikos.org/seer/index.php/oikos/article/viewArticle/ıog.

Cuervo-Cazurra, Alvaro. 20I2. "Extending Theory by Analyzing Developing Country Multinational Companies: Solving the Goldilocks Debate." Global Strategy Journal 2 (3): I53-67. doi:Io.IIII/j.20425805.2012.01039.X.

Cuervo-Cazurra, Alvaro, e Ravi Ramamurti. 20I4. Understanding Multinationals from Emerging Markets. Cambridge University Press.

Cyrino, Alvaro, e Betania Tanure. 2009. “Trajectories of Brazilian Multinationals: Coping with Obstacles and Opportunities in the Internationalization Process." In The Rise of Brazilian Multinationals: Making the Leap Fro Regional Heavyweights to True Multinationals. Elsevier.

Duanmu, Jing-Lin. 20I4. "State-Owned MNCs and Host Country Expropriation Risk: The Role of Home State Soft Power and Economic Gunboat Diplomacy." Journal of International Business Studies 45 (8). Academy of International Business: I044-6o. http://dx.doi.org/I0.I057/ jibs.20I4.I6.

Duarte, R De Siqueira. 20I4. "La Cooperación Brasileña No Es Gratis: Un Análisis de Los Intereses Contenidos En La Estrategia de Cooperación Internacional Al Desarrollo." Geopolítica (S). Revista de Estudios Sobre ... 4: 137-57. http://revistas.ucm.es/index.php/GEOP/article/ view/40363.

FDC. 20I4. "Ranking FDC Das Multinacionais Brasileiras 20I4." Rio de janeiro.

Fleury, Afonso, Maria T. L. Fleury, e Felipe Mendes Borini. 20I3. "Value-Chain Configurations of Brazilians EMNEs." In The Competitive Advantages of Emerging Market Multinationals, editado por Peter J Williamson, Ravi Ramamurti, Afonso Fleury, e Maria T. L. Fleury. Cambridge University Press.

Gartzke, Erik. 2000. "Preferences and the Democratic Peace." International Studies Quarterly 44 (2): I9I-2I2. doi:I0.IIII/0020-8833.00I55.

Guerin, Selen S., e Stefano Manzocchi. 2009. "Political Regime and FDI from Advanced to Emerging Countries." Review of World Economics I45 (I): 75-9I. doi:Io.I007/SI0290-009-0004-7.

Guillén, Mauro F, e Esteban García-Canal. 2009. "The American Model of the Multinational Firm and the 'New' Multinationals From Emerging Economies." The Academy of Management Perspectives 23 (2 ): 23-35. doi:I0.5465/AMP.2009.39985538. 
Guimarães, Samuel Pinheiro. 200I. "Inserção Internacional Do Brasil." Economia E Sociedade I7: I-3I.

Gupta, Nandini, e Xiaoyun Yu. 2007. "Does Money Follow the Flag?”

Henisz, Wj. 2000. "The Institutional Environment for Multinational Investment." Journal of Law, Economics, and Organization I6 (2): 334-64. doi:ıo.ıo93/jleo/ı6.2.334.

Hiratuka, Celio, e Fernando Sarti. 20II. "Investimento Direto E Internacionalização de Empresas Brasileiras No Período Recente.” I6ıo. Texto Para Discussão. Brasília.

Iglecias, Wagner. 20ıı. "Multilatinas E Governos Nacionais: Estratégias Para Um Novo Lugar Da América Latina No Capitalismo Contemporâneo?" Carta Internacional 6 (I): I3I-44.

Iglesias, Roberto Magno, e Katarina Costa. 20II. "O Investimento Direto Brasileiro Na África." Textos Cindes 27.

Jank, Marcos S, e M H Tachinardi. 2007. "Política Comercial, Negociações Internacionais E Internacionalização de Empresas.” Internacionalização E Os Países Emergentes. São Paulo, Atlas, 238-49.

Jensen, Nathan M, e René Lindstädt. 20I3. "Globalization with Whom: Context-Dependent Foreign Direct Investment Preferences."

Jensen, Nathan M. 2003. "Democratic Governance and Multinational Corporations: Political Regimes and Inflows of Foreign Direct Investment." International Organization 57 (03): 587-6ı6. doi:Io.IoI7/ So020818303573040.

Jensen, Nathan M. 2008. "Political Risk, Democratic Institutions, and Foreign Direct Investment." The Journal of Politics 70 (04): I040. doi:Io.IOI7/ So02238I608081048.

Kostova, Tatiana, e Kendall Roth. 2002. "Adoption of an Organizational Practice by Subsidiaries of Multinational Corporations: Institutional and Relational Effects." Academy of Management Journal 45 (I). Academy of Management: 215-33.

Kostova, Tatiana, e Srilata Zaheer. I999. "Organizational Legitimacy under Conditions of Complexity: The Case of the Multinational Enterprise." Academy of Management Review 24 (I). Academy of Management: 648I.

Lima, Maria Regina Soares De. 2005. "A Política Externa Brasileira E Os Desafios Da Cooperação Sul-Sul.” Revista Brasileira de Política Internacional 48 (I): 24-59. doi:I0.1590/S0034-73292005000100002.

Luxemburg, Instituto Rosa. 2009. Empresas Transnacionais Brasileiras Na 
América Latina: Um Debate Necessário. Editado por Campanha Justiça nos Trilhos, Instituto Políticas Alternativas para o Cone Sul (PACS), Instituto Rosa Luxemburgo Stiftung, Movimento dos Atingidos por Barragens, Rede Brasil sobre Instituições Financeiras Multilaterais, Rede de Justiça Ambiental, e Rede Social de Justiça e Direitos Humanos. Belém: Expressão Popular.

Malamud, Andrés. 20II. "A Leader Without Followers? The Growing Divergence Between the Regional and Global Performance of Brazilian Foreign Policy." Latin American Politics and Society 53 (3): I-24. http:// www.jstor.org/stable/4I342327 A Leader Without Followers?

Mathews, John A. 2006. "Dragon Multinationals: New Players in 2I St Century Globalization." Asia Pacific Journal of Management 23 (I). Springer: 5-27.

Menezes, Nadia B. 20I2. "A Política Governamental Brasileira de Incentivo À Internacionalização de Empresas ( I997-2005 ).” Seminário Brasileiro de Estudos Estratégicos Internacionais SEBREEI. Porto Alegre.

MIGA/World Bank Group. 2013. "World Investment and Political Risk." Washington, D.C. doi:Io.I596/978-I-4648-0039-9.

Milani, Carlos R S. 20I2. "Aprendendo Com a História: Críticas À Experiência Da Cooperação Norte-Sul E Atuais Desafios À Cooperação Sul-Sul." Caderno CRH 25 (65): 2II-3I. doi:Io.I590/SoIo349792012000200003.

Milani, Carlos R. S., e Tassia C. O. Carvalho. 20I3. "Cooperação Sul-Sul E Política Externa: Brasil E China No Continente Africano.” Estudos Internacionais I (I): II-35.

Milhorance, Carolina. 20I3. "A Política de Cooperação Do Brasil Com a África Subsaariana No Setor Rural: Transferência E Inovação.” Revista Brasileira de Política Internacional 56 (2): 5-22.

Ministério das Relações Exteriores. 2013. "Guia de Negócios - Angola."

Motta Veiga, Pedro, e Sandra P Rios. 20I4. "Os Investimentos Brasileiros No Exterior: Características, Motivações E Agenda de Políticas.” Breves Cindes 84 .

Oliveira, Guilherme Ziebell De. 2015. "Política Africana Do Brasil: Mudança Entre Lula E Dilma?" Conjuntura Austral 6 (29): 33-47.

Pandya, Sonal S. 2014. "Democratization and FDI Liberalization, I970 -2000." International Studies Quarterly, I970-2000.

Parente, Ronaldo C., Álvaro Bruno Cyrino, Nicole Spohr, e Flavio Carvalho De Vasconcelos. 2013. "Lessons Learned from Brazilian Multination- 
als' Internationalization Strategies." Business Horizons 56 (4): 453-63. doi:I0.1016/j.bushor.2013.04.003.

Ramamurti, Ravi, e Jitendra V Singh. 2009. Emerging Multinationals in Emerging Markets. Cambridge University Press.

Ramanzini, Haroldo, e Pedro Feliú Ribeiro. 2013. "As Relações Bilaterais Brasil-China : Uma Relação Em Processo de Afirmação." Carta Internacional 8: $165-87$.

Rugman, Alan M, e Alain Verbeke. 2004. "A Perspective on Regional and Global Strategies of Multinational Enterprises." J Int Bus Stud 35 (I). Academy of International Business: 3-I8. http://dx.doi.org/I0.I057/ palgrave.jibs.8400073.

Saraiva, Miriam Gomes. 2007. "As Estrategias de Cooperacao Sul-Sul Nos Marcos Da Politica Externa Brasileira de I993 a 2007." Revista Brasileira de Politica Internacional 50 (2): 42-59. doi:Io.I590/Soo3473292007000200004 .

Schneider, Friedrich, e Bruno S Frey. 1985. "Economic and Political Determinants of Foreign Direct Investment." World Development I3 (2): I6I-75. doi:Io.IoI6/0305-750X(85)90002-6.

Sennes, Ricardo, e Ricardo Mendes. 2009. "Políticas Públicas E Multinacionais Brasileiras." In A Ascensão Das Multinacionais Brasileiras. O Grande Salto de Pesos-Pesados Regionais a Verdadeiras Multinacionais. Rio de Janeiro: Elsevier.

Souza, André De Mello E. 20I2. "A Cooperação Para O Desenvolvimento SulSul: Os Casos Do Brasil, Da Índia E Da China." Cadernos Adenauer I3 (2): $75-88$.

Tuman, John P., e Craig F. Emmert. 2004. "The Political Economy of U.S. Foreign Direct Investment in Latin America - A Reappraisal.” Latin American Research Review 39 (3).

Vasconcellos, Patrícia Mara Cabral. 20I4. "As Construtoras Brasileiras E O Processo de Integração Regional Na América Do Sul.” Polis, Revista de La Universidad Bolivariana I3 (39): I-I6. http://www.redalyc.org/ articulo.oa?id=3053338800.

Vianna, Candice Sakamoto Souza. 20ıо. "Investimentos Diretos Brasileiros No Exterior Em Cenário de Risco Político: Evolução Recente E Impactos Na Política Externa.” Ministério das Relações Exteriores.

Vieitas, Deborah, e Isabel Aboim. 20I2. "África: Oportunidades Para Empresas Brasileiras." Revista Brasileira de Comércio Exterior, no. II6: 20-33.

Vigevani, Tullo, e Gabriel Cepaluni. 2007. "A Política Externa de Lula Da Sil- 
va: A Estratégia Da Autonomia Pela Diversificação." Contexto Internacional 29 (2): 273-335. doi:I0.1590/SoI02-85292007000200002.

Vigevani, Tullo, Marcelo F. De Oliveira, e Rodrigo Cintra. 2003. "Política Externa No Período FHC: A Busca de Autonomia Pela Integração." Tempo Social I5 (2): 3I-6I. doi:IO.I590/SoI03-20702003000200003.

Vilas-Bôas, Júlia Covre. 20ıı. “Os Investimentos Brasileiros Na África No Governo Lula : Um Mapa.” Meridiano 47 I2 (I28): 3-9.

Vilas-Bôas, Júlia Covre. 20I4. "O BNDES E a Internacionalização Das Empresas Brasileiras Na África Nos Anos 2000.” http://obs.org.br/index. php?option=com_k2\&view=item\&id=723:o-bndes-e-a-internacionalizacao-das-empresas-brasileiras-na-africa-nos-anos-2000\&Item$\mathrm{id}=\mathrm{I} 32$.

Visentini, Paulo G. Fagundes. 20I4. "África E as Potências Emergentes: O Sul E a Cooperação Profana." Austral: Revista Brasileira de Estratégia E Relações Internacionais 3 (5): 4I-68.

Visentini, Paulo G. Fagundes, e André Luiz Reis Da Silva. 20ıо. "Brazil and the Economic, Political, and Environmental Multilateralism: The Lula Years (2003-2010)." Revista Brasileira de Política Internacional 53: 5472. doi:I0.1590/S0034-73292010000300004.

Voeten, Erik. 2000. Clashes in the Assembly. International Organization. Vol. 54. doi:I0.II62/00208I80055II54.

White, Lyal. 2oIo. "Understanding Brazil's New Drive for Africa." South African Journal of International Affairs I7 (2): 22I-42. doi:I0.IO80/I0220 461.2010.494345.

$\mathrm{Xu}$, Dean, e Oded Shenkar. 2002. "Institutional Distance and The Multinational Enterprise." Academy of Management Review 27 (4): 608-18. doi:10.5465/AMR.2002.7566108.

\section{RESUMO}

A literatura brasileira de relações internacionais tem dado cada vez mais atenção ao papel desempenhado pelas transnacionais brasileiras na inserção internacional do Brasil. Nesse contexto, chama a atenção a presença de empresas brasileiras na África e, em especial, em Angola. Alguns países da África Subsaariana são entendidos como países com potencial para os investimentos, especialmente devido à similaridade dos desafios para o desenvolvimento e das oportunidades de exportação da expertise brasileira em setores como a agricultura, mineração e construção civil. O objetivo deste trabalho é tentar capturar possíveis efeitos das relações governamentais entre Brasil e Angola sobre as a atuação internacional de empresas brasileiras. Nossa hipótese é que o ambiente de negócios entre os países foi favorecido por um concomitante alinhamento político internacional, fruto das mudanças na orientação da PEB. 


\section{PALAVRAS-CHAVE}

Brasil; Angola; Alinhamento Político Internacional; Investimento Brasileiro Direto; Cooperação Sul-Sul.

Recebido em 28 de junho de 2016. Aprovado em 01 de julho de 2016. 